\title{
Dialektika Model Kepemimpinan Pendidikan Islam dari Berbagai Perspektif di
}

\section{Era Disruptif}

\author{
Nurhidayah $^{1}$, Sofyan Sauri², Faiz Karim Fatkhullah ${ }^{3}$, Siti Honiah Mujiati ${ }^{4}$ \\ Universitas Islam Nusantara Bandung
}

hynur82@gmail.com , faizkarim@uninus.ac.id

\begin{abstract}
This article analyzes the dialectical problem of educational leadership models from various perspectives in the disruptive era. Leadership is one of the crucial issues in the management of education. The uneven quality of education at both the central and regional levels is a homework that still needs to be completed by the world of education. National Education Standards that have been formulated explicitly to be achieved as School or Madrasah thresholds are still stuck on administrative fulfillment only. The planning, implementation, evaluation and follow-up plans of the School Work Program do not yet reflect the needs of the school community. An educational leader who has the appropriate qualifications and competencies is needed to bring schools or madrasas to excel in this disruptive era. A complete understanding of the proper leadership model of educational leaders is one of the important knowledge for a leader to be able to improve the quality of the education of the institution he leads. Based on the background above, this paper presents various models of educational leadership from a theological perspective, a philosophical psychological perspective, sociology in order to improve the quality of educational leadership in the disruptive era.
\end{abstract}

Key words: Dialectic Model of leadership, Education, Disruptive.

\begin{abstract}
Abstrak
Artikel ini mengurai persolan dialektika model kepemimpinan pendidikan dari berbagai perspektif di era disruptif. Kepemimpinan adalah salah satu persolan yang krusial dalam pengelolaan pendidikan. Belum meratanya mutu pendidikan baik tingkat pusat maupun di daerahmenjadi pekerjaan rumah yang masih harus diselesaikan dunia pendidikan. Standar Nasional Pendidikan yang telah dirumuskan secara ekplisit untuk dicapai sebagai ambang batas Sekolah atau Madrasah masih terjebak pada pemenuhan administrasi saja. Kegiatan perencanaan, pelaksanaan, evaluasi dan rencana tindak lanjut dari Program Kerja Sekolah belum mencerminkan kebutuhan warga sekolah. Dibutuhkan seorang pemimpin pendidikan yang memiliki kualifikasi dan kompetensi yang sesuai untuk membawa Sekolah atau Madrasah menjadi unggul di era disruptif ini. Pemahaman yang utuh tentang model kepemimpinan yang tepat dari para pemimpin pendidikan menjadi salah satu pengetahuan penting dari seorang pemimpin untuk mampu meningkatkan Mutu Pendidikan lembaga yang dipimpinnya. Berdasarkan latar belakang di atas tulisan
\end{abstract}


ini menyajikan berbagai model kepemimpinan pendidikan dari perspektif teologis, perspektif psikologi filosofis, sosiologi dalam rangka meningkatkan kualitas kepemimpinan pendidikan tersebut di era disruptif.

Kata Kunci: Dialektika model kepemimpinan, Pendidikan, Disruptif.

\section{LATAR BELAKANG}

Badan Pusat Statistik (BPS) mencatat Indeks Pembangunan Manusia (IPM) Indonesia 2021 mencapai 72,29, atau tumbuh melambat 0,49 persen dibandingkan dengan capaian tahun sebelumnya. ${ }^{1}$ Peningkatan tersebut terjadi pada peningkatan lama rata-rata pendidikan dan kesehatan. Meningkatnya lama pendidikan anak di Indonesia idealnya harus berbanding lurus dengan meningkatnya keimanan peserta didik, dan kokohnya akhlakul karimah. Siswa mandiri dan berkebhinekaan global. Peran penting pemimpin pendidikan sebagai pengelola utama dalam sebuah institusi pendidikan sangat diharapkan. Pemimpin yang memiliki kualifikasi dan kompetensi sebagai amanat Undang-Undang system Pendidikan Nasional nomor 20 Tahun 2003, Bab II yang menyatakan mendesaknya kebutuhan kepemimpinan pendidikan yang mampu mengelola pendidikan Indonesia menghadapi era 4.0 dan 5.0.

Peraturan Menteri Pendidikan Nasional nomor 16 tahun 2007 tentang standar akademik Kepala sekolah/madrasah dan Permendikbud nomor 13 tahun 2007 tentang standar kompetensi Kepala Sekolah, Peraturan Menteri Pendidikan dan Kebudayaan tahun 2018 tentang Standar Kompetensi Kepala Sekolah/Madrasah menyebutkan bahwa kepala Sekolah adalah guru yang diberi tugas tambahan. Oleh karena itu ada 5 kompetensi yang harus dimiliki oleh seorang Kepala Sekolah/Madrasah yaitu kompetensi kepribadian, kompetensi social, kompetensi Kepala Sekolah/Madrasah yaitu kompetensi kepribadian, kompetensi social, kompetensi bisa diberi tugas tambahan sebagai Kepala Sekolah/Madrasah adalah guru yang memiliki lima kompetensi tersebut.

Peraturan tentang Standar Kepala Sekolah/Madrasah yang dikeluarkan oleh pemerintah tersebut didasarkan pada adanya evaluasi rendahnya mutu pendidikan Indonesia dari tahun ke tahun. Sehingga berbagai tahapan dan prosedur dalam rekruitment Calon Kepala sekolah dilakukan oleh Kementrian Pendidikan dan

\footnotetext{
${ }^{1}$ Badan Pusat statistic. https://ekonomi.bisnis.com/read/20211116/9/1466566/indeks-pembangunanmanusia-2021-
} 
Kebudayaan Indonesia. Program Penguatan Kepala Sekolah diberikan kepada Kepala Sekolah yang dalam masa jabatan, sedangkan untuk Calon Kepala Sekolah diberikan Pendidikan dan pelatihan untuk meningkatkan lima kompetensi utama seorang Kepala Sekolah/Madrasah. Berbagai program tersebut dilakukan untuk menyiapkan Calon pemimpin pendidikan yang diharapkan mampu merencanakan, melaksanakan, menngevaluasi dan Menyusun rencana tindak lanjut pengembangan sekolah/madrasah yang berbasis asset.

Hasil survey penulis terhadap 100 Kepala Sekolah Dasar, Kepala Taman KanakKanak dan Kepala Sekolah Menengah Pertama di Jawa yaitu Kebumen, Cilacap, Sragen, Magelang dan Semarang menunjukkan bahwa mereka memiliki mimpi dan keinginan untuk membawa lembaga yang dipimpinnya menjadi lembaga pendidikan unggulan. Sekolah yang memiliki

banyak murid dan memiliki prestasi baik di tingkat Dabin, Kecamatan, Kabupaten, Propinsi, Nasional bahkan juara Internasional. Namun demikian mimpi tersebut belum mampu

diwujudkan. Setelah melalui FGD (forum Grup Discussion) baik secara virtual dan offline, faktor yang menjadi penyebab belum tercapainya mimpi tersebut adalah karena belum maksimalnya peningkatan 5 kompetensi Kepala Sekolah/Madrasah yang seharusnya dimiliki. Hubungan yang tidak harmoni antar pemimpin dan warga sekolah, kurangnya rasa kebersamaan, minimnya rasa memiliki sekolah, monotonnya pembelajaran guru dan lain sebagainya.

Pada aspek perencanaan program kerja Sekolah, Kepala Sekolah/Madrasah masih menyusun sendiri tanpa melibatkan seluruh warga sekolah. Padahal secara manajerial penyusunan rencana kerja Sekolah idealnya berdasar pada hasil Evaluasi Diri Sekolah Tahun sebelumnya. Penyusunannya dilakukan bersama oleh Kepala sekolah dengan melibatkan semua warga sekolah, sehingga program rencana kerja Kepala Sekolah/madrasah sesuai dengan kebutuhan dan mengatasi permasalah Sekolah/Madrasah tersebut. Program Kerja Pemimpin pendidikan di Tingkat sekolah/Madrasah tersebut sesuai dengan kebutuhan di lapangan. Program-program Sekolah/Madarasah adalah pilihan solusi terbaik dalam mengatasi masalah pembelajaran yang ada di sekolah. Tidak ada rasa curiga dan konflik kepentingan diantara warga sekolah/Madrasah.

Kepala Sekolah/Madrasah adalah pemimpin dalam pengelolaan pendidikan di 
tingkat Sekolah/Madrasah. Pemimpin yang mampu mengatur, melindungi dan membawa institusi yang dipimpinnya menjadi institusi yang solid. Pemimpin bukan hanya sekedar memimpin sesuai keinginan namun kebutuhan. Sebuah idiom menarik adalah bahwa seorang pemimpin hendaknya membumi namun juga melangit. Membumi bahwa pemimpin pendidikan dituntut untuk mampu merakyat diterima semua warga sekolah, serta mampu menyusun rencana kerja sekolah yang sesuai kebutuhan warga sekolah/Madrasah tersebut. Sebagai contoh peningkatan kemampuan guru untuk memanfaatkan media pembelajaran berbasisi Informasi dan Teknologi (IT) melalui IHT (In House Training) sehingga outcome yang didapat guru kreatif membuat media pembelajaran yang berbasisi IT, siswa pun senang dan tidak merasa bosan mengikuti pembelajaran. Hasilnya prestasi siswa meningkat baik dalam ranah kognitif, psikomotorik dan afektif.

Pemimpin pendidikan harus mampu memahami bagaimana konsep kepemimpinan pendidikan yang ideal. Kepemimpinan Pendidikan adalah sebuah kepemimpinan yang dilakukan untuk mengelola manusia dan memanusiakan manusia. Kepemimpinan pendidikan subyek yang dipimpin adalah manusia, pemimpinnya manusia, obyek yang dipimpin juga manusia. Maka

setiap pemimpin pendidikan yang mengelola pendidikan apalagi di era disruftif dimana kemajuan teknologi, komunikasi dan pengetahuan terus berkembang maka pemimpin harus memahami model kepemimpinan pendidikan yang akan dia pilih dan laksanakan. Kepemimpinan pendidikan yang gagap di era disruptif tetapi sebaliknya mampu menjawab situasi dan kondisi, itulah yang diharapkan dari kompetensi kewirausahaan.

Kompetensi kewirausahaan adalah sebuah kompetensi yang menunjukkan resiliensi seorang pemimpin dalam menghadapi sebuah kondisi. Setiap masalah diidentifikasi akar permasalahnnya, lalu direnungkan bersama semua warga sekolah apa penyebabnya, apa solusi dan impian setiap warga sekolah yang ia pimpin, lalu dipilihlah solusi terbaik. Sehingga ketika contoh jumlah siswa sedikit dan menurun, pemimpin pendidikan bukan sibuk mencari kambing hitam, namun berpikir positif dan berlaku positif untuk mengatasi masalah tersebut. Mengutip Gaut (2007) dalam Paris3 bahwa the moral beauty views states that moral virtue is beautiful and moral vice is ugly. Pernyataan ini mengandung pengertian bahwa dalam konteks kepemimpinan pendidikan seorang pendidik harus membiasakan diri untuk mengedepankan moral beauty (keindahan moral) 
karena keindahan moral adalah kebajikan moral. Ini selaras dengan amanat peraturan Menteri Pendidikan dan Kebudayaan tentang kompetensi yang harus dimiliki seorang Kepala Sekolah atau Madrasah.

Berdasarkan latar belakang di atas penulis ingin mengetahui

1. Bagaimana Model Kepemimpinan Pendidikan dalam Perspektif Teologis, Psikologis, Fisiologis dan Sosiologis?

2. Bagaimana model kepemimpinan Pendidikan di Era 4.0 dan society 5.0?

\section{HAIL DAN PEMBAHASAN}

Kepemimpinan Pendidikan menurut Sauri merupakan sebuah upaya yang terorganisir, berencana dan berlangsung kontinu(terus menerus sepanjang hayat) ke arah membina manusia/anak didik menjadi insan paripurna, dewasa dan berbudaya (civilized). ${ }^{2}$ Berdasar konsep tersebut maka kepemimpinan pendidikan yang baik adalah sebuah keniscayaan untuk mencapai tujuan bersama yang ingin dicapai. Rifai (2003) menyebutkan bahwa kepemimpinan pendidikan adalah seni mengarahkan dan mempengaruhi orang dengan cara kepatuhan, kepercayaan, kehormatan dan kerjasama dalam mencapai tujuan bersama. Selanjutnya Stephen P.Robbins (1983) mendefinisikan kepemimpinan adalah kemampuan untuk mempengaruhi sebuah kelompok dalam mencapai tujuan. Kepemimpinan tidak bisa dilakukan secara asal. Beberapa konsep Kepemimpinan secara teologis, psikologis, sosiologis)

\section{Kepemimpinan Pendidikan dalam Perspektif Teologis}

Kepemimpinan Pendidikan dalam perspektif Teologis adalah sebuah kepemimpinan yang didasarkan pada nalar agama, norma agama, hukum agama. Dalam konteks ini adalah dalil yang dipakai adalah Quran dan Hadits. Hal ini karena kepemimpinan dalam Islam adalah sebuah amanah yang harus dipertanggungjawabkan. Beberapa dalil Quran yang menjadi dasar dalam menjalankan kepemimpinan pendidikan adalah firman Allah SWT adalah sebagai berikut:

1. Al Quran surat An Nisa ayat 59

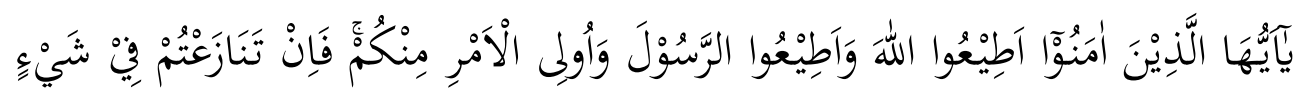

\footnotetext{
${ }^{2}$ Panos Paris. 2018. The empirical Case For Moral Beauty. Australia: Australian Journal of philosophy. Volume 96 number 4
} 


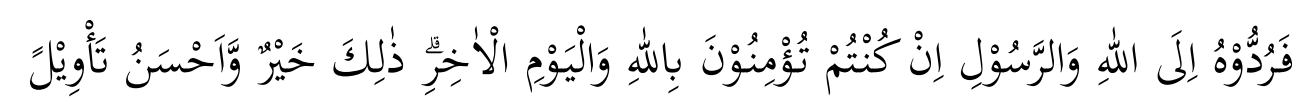

yang artinya "Wahai orang-orang yang beriman, taatilah Allah dan taatilah Rasul (Muhammad) dan ulil amri diantara kamu. Kemudian jika kamu berlainan pendapat tentang sesuatu, maka kembalikanlah ia kepada Allah (Al Quran) dan rasul (sunnahnya), jika kamu benar-benar beriman kepada Allah dan hari kemudian, yang demikian itu lebih utama bagimu dan lebih baik akibatnya.. ${ }^{3}$

2. Surat Al Baqarah ayat 30 yang artinya:

"Dan ingatlah ketika Tuhanmu berfirman kepada para malaikat: sesunguhnya Aku hendak menjadikan seorang khalifa di muka bumi. Mereka berkata:”Apakah Engkau hendak menjadikan khalifah orang yang merusak dan menumpahkan darah disana, sedangkan kami bertasbih memuji-Mu dan mensucikan nama-Mu? "Dia berfirman, sungguh, aku mengetahui apa yang tidak kamu ketahui”.

Adapun Hadits Rasulullah SAW yang bisa menjadi pedoman dalam kepemimpinan pendidikan menurut Sauri (2021: 96) adalah sebagai berikut:

1. Hadits Mutafaq'alaih bahwa dari Umar r.a ia berkata: bersabda Rasulullah SAW setiap kalian adalah pemimpin, dan kalian akan ditanya tentang kepemimpinan kalian.

2. Hadits dari riwayat Hakim yaitu: "Barangsiapa yang memimpin suatu urusan kaum muslimin lalu ia mengangkat seseorang pada hal ia menemukan orang yang lebih pantas untuk kepentingan ummat Islam dari orang itu, maka dia telah berhianat kepada Allah dan rasul Nya (H.R.Hakim)

\section{Kepemimpinan Pendidikan dalam Perspektif Filosofis}

Secara istilah falsafah diartikan dengan gagasan dan pandangan yang mendasar yang dimiliki oleh seseorang atau masyarakat atau komunitas. Kepemimpinan dalam perspektif filosofis mendasarkan pada konsep kepemimpinan pendidikan maka bila dasarkan pada perspektif folosofis ini maka beberapa pilihan. Seperti konsep pemikiran kepemimpinan pendidikan bila merunut pada konsep idealism Plato $^{4}$ yang menyatakan bahwa manusia senantiasa mengedapankan pikiran dan jiwanya, pada konsep pola pemimpin yang ada akan berusaha sebisa mungkin untuk mencapai tujuan yang ingin

\footnotetext{
${ }^{3}$ https://pontren.com/2021/01/24/surat-an-nisa-ayat-59/diakses 15 Januari 2022.

${ }^{4}$ Dalam Sofyan sauri. 2021. H. 38-39.
} 
dicapai, dan seringkali hanya berpusat pada Kepala Sekolah yang terbangun anak buah dan atasan. Hal ini karena konsep filsafat idealism menekankan pada idealisme yang memiliki tujuan yang sempurna dan ingin dicapai. Berbeda dengan konsep kepemimpinan filosofis idealis, maka konsep kepemimpinan pendidikan dalam pandangan realism Aristoteles ${ }^{5}$ menekankan pada adanya realism, kenyataan. Bahwa kepemimpinan tidak lagi hanya ditujukan untuk dicapai harus dicapai tetapi disesuaikan dengan kenyataan dan dilaksankan sesuai logika.

Konsep filosofis lain tentang kepemimpinan pendidikan yang kontekstual seperti konsep Ki Hajar Dewantara atau KHD yaitu Ing ngarso sung tulodho Ing madyo mangun karso Tut wuri handayani. Bahwa seorang pemimpin ketika di depan hendaknya ia memberi contoh, dan ketika di tengah ia bekerja atau berkarya, namun apabila ia di belakang ia memberi motivasi, semangat kepada yang lain. Konsep kepemimpinan pendidikan yang humanis adalah yang senantiasa dilandasi dengan prinsip momong, among, ngemong. Bahwa sebagai Momong, artinya seorang pemimpin harus mampu mengasuh, melindungi. Among artinya mengajari, membina dengan menyesuaikan dengan kondisi dan situasi serta karakter yang dipimpin. Selanjutnya Ngemong artinya seorang pemimpin harus mampu merangkul, mengasuh dengan memberikan kenyamanan, rasa aman. Pemimpin pendidikan dari sikap intimidasi, kekerasan baik verbal, psikis, fisik dan seksual.

\section{Kepemimpinan Pendidikan dalam Perspektif Psikologis}

Dalam sebuah kepemimpinan pendidikan dalam perspekftif psikologis menempatkan kepemimpina pendidikan yang konkret, agar mampu mempengaruhi bawahannya. Dalam perspektif ini sepakat bahwa ada tiga pendekatan dalam kepemimpinan, yaitu sifat, perilaku dan situasional ${ }^{6}$.

1. Pendekatan sifat ${ }^{7}$, teori menekankan pada diri pemimpin itu sendiri. Teori ini lebih dikenal dengan teori pembawaan. Bahwa pemimpin memiliki ciri-ciri atau sifat tertentu dalam kepemimpinannya.

2. Pendekatan Perilaku ${ }^{8}$ bahwa teori ini menekankan bukan pada bagaimana sifat pemipin tetapi pada apa yang dilakukan pemimpin dalam kepemimpinannya.

\footnotetext{
${ }^{5}$ Loc.it. h.39.

${ }^{6}$ Naurzaima dalam Sofyan, 2021. h.100

${ }^{7}$ Wursanto dalam Sauri.2021. Manajemen Kepeimpina Pnedidikan. Bandung: UPI PRESS

${ }^{8}$ Ibid.h. 235
} 
3. Pendekatan situasional, pendekatan ini menekankan pada bagaiaman gaya kepemimpinan seseorang dalam pengambilan keputusannya berdasar situasi tertentu.

\section{Kepemimpinan Pendidikan dalam Perspektif Sosiologis}

Konsep kepemimpinan pendidikan dari perspektif sosiologis sebagaimana akar dari sosiologi ${ }^{9}$ sendiri sebagai proses social, maka kepemimpinan pendidikan dalam perspektif ini menekankan pada sebuah konsep bahwa kepemimpina adalah hubungan social antara pemimpin dan bawahan, teman sejawat dan warga sekolah yang didalamnya ada wali murid, komite, siswa, guru dan tenaga kependidikan. Perlu adanya rekayasa social sebuah lembaga pendidikan agar tujuan pendidikan tercapai. Perlu pranata aturan yang disepakati bersama sehingga tercapai harmonisasi dalam kepemimina pendidikan yang dijalankan. Dalam konteks ini maka seorang pemimpin harus memahmi benar social, ekonomi, budaya, politik yang ada di lembaga yang ia pimpin. Oleh karena itu seorang pemimpin menurut Stephen P Robbins ${ }^{10}$ menyatakan bahwa a group as two or more individuals, interacting and interdependent, who have come together to achive particular objectives. Berdasar ungkapan itu maka untuk meningkatkan efektifitas kerja sebuah organisasi atau lembaga pemimpin pendidikan harus memahami kelompok dengan berbagai aspeknya dan tidak bisa ditawar. Organisasi pendidikan adalah sebagai sebuah kelompok orang maka akan terjadi (1) proses interaksi, (2)ada struktur yang mengatur, (3) ada norma atau regulasi, (4) kepemimpinan.

Oleh karena dalam konsep sosiologis ini untuk selanjutnya dalam kepemimpinan pendidikan perlu dibuat tim, ${ }^{11}$ yaitu sebuah kelompok yang terdiri dari orang yangsudah matang terdiri dari orang-orang yang saling bergantung, memiliki motivasi dan komitmen untuk mencapai tujuan atau sasaran tertentu. Sebuah kelompok yang siap berkembang dan mempunyai visi yang jelas dan terarah.

\section{Teori-teori tentang Kepemimpinan}

Kondisi social budaya seseorang seringkali akan berpengaruh pada bagaimana

\footnotetext{
${ }^{9}$ Sauri.h.178

${ }^{10}$ Dalam Sudaryono. 2017. Pengantar Manajemen: Teori dan Kasus. Yogyakarta: CAPS( Center for Academic Publishing Service). H. 218.

${ }^{11}$ Ibid. h.2019.
} 
seorang menjadi pemimpin dan memimpin lembaganya. Wursanto ${ }^{12}$ Berikut beberapa teori kepemimpinan yaitu:

1. Teori Kelebihan

Teori ini beranggapan bahwa seseorang akan menjadi pemimpin apabila ia memiliki kelebihan dari para pengikutnya. Pada dasarnya kelebihan yang dimiliki oleh seorang pemimpin. Teori ini terbagi lagi mencakup teori kelebihan ratio, teori kelebihan rohaniah, teori kelebihan badaniah.

\section{Teori Sifat}

Bahwa seseorang yang menjadi pemimpin yang baik apabila memiliki sifat-sifat lebih dari pada yang dipimpin. Menurut Keith Devis ${ }^{13}$ sifat itu adalah:

a. Kecerdasan

b. Kedewasaan dan keluwesan

c. Motivasi dan dorongan berprestasi

d. Sikap-sikap hubungan kemanusiaan

3. Teori keturunan

Teori ini mengatakan bahwa seseorang dapat menjadi pemimpin karena keturunan atau warisan.

\section{Teori kharismatik}

Tori ini menyatakan bahwa seseorang bisa menjadi pemimpin ketika memiliki charisma(pengaruh) yang sangat besar.

\section{Teori bakat}

Disebut juga teori ekologis karena berpandangan pemimpin adalah lahir karena bawaan atau bakat.

6. Teori social, yang beranggapan bahwa semua orang bisa jadi pemimpin.

7. Teori kelompok, ${ }^{14}$ teori ini berpandangan tujuan organisasi bisa dicapai ketika ada komunikasi atara pemimpin dan pengikutnya.

8. Teori situasional yang berpendapat bahwa beberapa kondisi berpengaruh terhadap kepemimpinan, kecakapan da perilakunya termasuk pelaksanaan kerja dan kepuasan pengikutnya.

9. Teori Kepemimpinan Kontingensi, menurut Fiedler dalam Sauri dikatakan bahwa teori ini berpandangan bahwa gaya kepemimpina berpengaruh terhadap situasi yang

\footnotetext{
${ }^{12}$ Sofyan Sauri. 2021. Manajemen Kepemimpinan Pendidikan.h.234-244.

${ }^{13}$ Sauri (2021:235)

${ }^{14}$ Moftah thoha (2003) dalam Sauri 2021.h.237
} 
menyenangkan, sehingga ada hubungan antara pemimpin dan anggota, derajat struktur tugas yang jelas dan urut serta posisi kekuasaan dicapai lewat otoritas yang formal.

Kepemimpinan seseorang akan berhasil atau tidak dalam mencapai tujuan dalam pelaksanaan kepemimpinan pendidikan di era disruptif ini bila tipe kepemimpinan yang dipilih tepat. Berikut jenis-tipe-tipe kepemimpinan dalam Sauri ${ }^{15}$, yaitu:

a. Kepemimpinan otokrasi (bersifat dikatotator dan direktif),

b. Kepemimpinan demokrasi, acuan bahwa pendapat orang banyak lebih baik dari pendapatnya sendiri, karena akan ada rasa tanggungjawab bawahan

c. Kepemimpinan Laissez faire (bebas)

d. Kepemimpinan partisipatif

e. Kepemimpinan paternalistik (Kebapakan)

f. Kepemimpinan yang berorientasi pada tujuan

g. Kepemimpinan Militeristik

h. Kepemimpinan situasional

i. Kepemimpinan dalam perspektif Islam,

Kepemimpinan dalam Perskpektif Islam dalam Sauri, yaitu: ${ }^{16}$

1. Tidak mengambil orang kafir sebagaipemimpin (surat An Nisa 144)

2. Tidak mengangkat pemimpin yang suka mempermainkan agama Islam

3. Pemimpin harus memiliki keahlian di bidangnya (H.R. Bukhori dan Muslim)

4. Pemimpin harus diterima, dicintaidan mencintai umatnya (yang dipimpin)

5. Pemimpin harus mendahulukan kepentingan umat, adil, menegakkan syariat

\section{Kepemimpinan Pendidikan di Era Disruptif 4.0 dan society 5.0}

Di era disruptif ini dimana ditandai dengan ketidakpastian karena cepatnya perkembangan teknologi dan komunikasi serta ilmu pengetahuan, maka tuntutan terhadap pendidikan sangat berat. Kepemimpinan pendidikan di masa ini membutuhkan tenaga ekstra, mental ekstra untuk mampu membawa lembaganya agar mampu

15 Sauri. 202. h: 239

${ }^{16}$ Sauri. 2021.h.244 
mencetak lulusan yang beriman, bertakwa, berbudaya namun tidak tertinggal oleh zaman. Dibutuhkan disruptive Educational leader, yaitu para pemimpin pendidikan yang bisa berhasil membawa keluar organisasi yang dipimpin dari perangkap masa lalu dan mendisrupsi organisasi menjadi sehat. Karena Pemimpin yang masih mempertahankan gaya lama akan tertinggal atau ditinggalkan. Contoh pemimpin yang fenomenal adalah Jeff Bezos, CEO Amazon.Com.

Pemimpin pendidikan di era disruptif dituntut untuk mampu memberikan kinerja untuk mampu memberikan karya terbaik selama dalam mengelola institusinya. Ivancevich ${ }^{17}$ menyatakan bahwa kinerja menunjukkan kemampuan dan ketrampilan pekerja. Konsep ini menunjukkan bahwa kemampuan kompetensi sumber daya manusia yang dimiliki sebuah lembaga pendidikan atau organisasi mulai kemampuan kognisi, psikomotor dan afeksi. Mengutip konsep Habitus Bordieu ${ }^{18}$ maka dalam bukan hal mudah dan perlu kerja keras dan kerja cerdas dalam melaksanakan kepemimpinan pendidikan dalam mengubah paradigma berpikir warga Sekolah//Madrasah yang dipimpinnya.

Karakter Pemimpin Disruptif menurut Faisal Hoque pendiri lembaga Shadoka dan penulis buku Everything Connect: How to Transform and lead in the age of creativity, innovation \& Sustainability, 2014 memiliki ciri-ciri sebagai berikut::

1. Selalu mencari Kebenaran, Jujur terhadap diri sendiri

2. Mampu membimbing anggotanya dalam keadaan apa pun, dalam setiap kondisi apapun.

3. Berani mengambil keputusan dan resiko berdasarkan intuisi dan mampu menjelaskan kepada anggotanya mengenai alasan, tujuan dan bagaimana cara mewujudkannya.

4. Berani mendobrak cara lama, terutama yang menghambat kemajuan perusahaan.

5. Dia tumbuh dan berkembang bersama ketidakpastian, tidak terlena oleh comfort zone.

\section{KESIMPULAN}

Model kepemimpinan pendidikan dari berbagai perspektif baik teologis, filosofis, psikologis, sosiologis adalah sebuah konsep yang bisa dijadikan pedoman

\footnotetext{
${ }^{17}$ Ivancevich, Konopaske, Matteson dalam Muhammad Busro. 2018. Teori-Teori Manajemen Sumber Daya Manusia. Jakarta: Prenadamedia Group. H. 87.

${ }^{18}$ Ed. John B.Thomshon. 1992. Language and Symbolic Power Pierre Bordieu. Carnwall: Polity Press
} 
seorang calon pemimpin pendidikan. Secara teologis menunjukkan bahwa kepemimpinan pendidikan hendaknya membumi dan melangit, dalam arti programnya manusia, memanusiakan manusia namun juga bisa dipertanggungjawabkan kepada Tuhan Yang Maha Esa. Pada perspektif filosofis dari Plato dan Aristoteles menunjukkan bahwa kepemimpinan memang harus idealis untuk mencapai tujuan yang dicita-citakan. Namun disisi lain juga disesuaikan dengan realita, kondisi. Dari aspek sosiologis kepemimpinan pendidikan adalah tentang manusia, pengelola (pemimpin manusia)yang dipimpin juga manusia maka dalam proses kepemimnan pendidikan juga harus tetap memperhatikan pengikut atau warga sekolah merasa tidak bisa bersosialisasi, karena mereka memang mahluk social. Adapun perspektif psikologis, bahwa menjadi pemimpin harus ingat bahwa setiap manusia ingin dihargai kemanusiannya, ketika pemimpin mampu mencontoh Rasulullah Muhammad SAW dan penerusnya Ki Hajar Dewantara dengan Momong, among, Ngemongnya, maka siapapun yang dipimpin akan semangat untuk mencapai tujuan pendidikan di sekolah Bapak/ibu. Di masa disruptif dibutuhkan pemimpin yang mampu mengayomi, melindungi, mewadahi seluruh aspirasi warga sekolah lebih terbuka dan situasional sesuai teladan Rasulullah SAW dan konsep Ki Hajar Dewantara.

\section{DAFTAR PUSTAKA}

Charles J.Keating.1986. Kepemimpinan: Teori dan Pengembangannya. Yogyakarta: Kanisius

Ed. John B.Thomshon. 1992. Language and Symbolic Power Pierre Bordieu. Carnwall: Polity Press

\section{https://onlinedegrees.sandiego.edu/effective-educational- leadership/}

https://www.republika.co.id/berita/pu1zda282/kepemimpinan- dan-perkembanganteknologi-di-era-disruptive-part1

https://www.tandfonline.com/toc/tedl20/current

Ivancevich,dkk. 2018. Teori-Teori Manajemen Sumber Daya Manusia. Jakarta: Prenadamedia Group.

Sofyan Sauri. 2021. Manajemen Kepemimpinan Pendidikan. Jakarta: Rumah Literasi Publishing. Sudarsono. 2017. Pengantar Manajemen: Teori dan Kasus. Yogyakarta: CAPS 